Original Research Paper

\title{
Study of Energy Types: Fossil, Nuclear and Renewable Energies and their Evaluation in Terms of Environmental Pollution and Economically
}

\author{
${ }^{1}$ Sara Abdollahi, ${ }^{2}$ Meysam Madadi, ${ }^{3}$ Soleyman Ghorbanzadeh, \\ ${ }^{4}$ Kaveh Ostad-Ali-Askari, ${ }^{5}$ Vijay P. Singh and ${ }^{6}$ Saeid Eslamian \\ ${ }^{1}$ Department of Environmental Science, Faculty of Natural Resources and Desert Studies, Yazd University, Yazd, Iran \\ ${ }^{2}$ Department of Environmental Science, Gorgan University of Agriculture Science and Natural Resources, Gorgan, Iran \\ ${ }^{3}$ Ph.D. Student of Natural Resources and Environment Engineering, \\ Air Pollution, Islamic Azad University, Tonekabon Branch, Iran \\ ${ }^{4}$ Department of Civil Engineering, Isfahan (Khorasgan) Branch, Islamic Azad University, Isfahan, Iran \\ ${ }^{5}$ Department of Biological and Agricultural Engineering and Zachry \\ Department of Civil Engineering, Texas A and M University, \\ 321 Scoates Hall, 2117 TAMU, College Station, Texas 77843-2117, USA \\ ${ }^{6}$ Department of Water Engineering, Isfahan University of Technology, Isfahan, Iran
}

Article history

Received: 06-05-2018

Revised: 19-05-2018

Accepted: 17-07-2019

Corresponding Author:

Kaveh Ostad-Ali-Askari

Department of Civil

Engineering, Isfahan

(Khorasgan) Branch, Islamic

Azad University, Isfahan, Iran

Email: koa.askari@khuisf.ac.ir

\begin{abstract}
Unwise and increasing exploitation of various energy carriers, including oil, gas and coal, has made countries to focus on two major issues, namely running out fossil fuels, as well as environmental pollution. Hence, one of the main priorities of energy policy is to diversification of energy sources, as well as finding a safe, cheap and nonpolluting energy source (devoid of greenhouse gases). Therefore, nuclear energy is important. In this regard, the main purpose of this paper is to examine the effect of energy consumption on the quality of the environment and the introduction of the best economically efficient option for energy production. In this research, we conducted a literature search incorporating keywords of nuclear energy, nuclear fission, fossil fuel, greenhouse effect in Persian and English databases in a structured manner and retrieved the papers and articles dealt with benefits and disadvantages of nuclear energy as well as its environmental impacts and subsequently they analyzed in a descriptive manner. In this study, while studying nuclear energy, fossil fuels and renewable energy, we tried to introduce a suitable replacement of these energies to fossil fuels, taking into account the economic and environmental perspectives resulting from it. Among all types of energy sources, nuclear energy may have the least impact on the environment, including water, soil and air and is a source free from gases. In addition to all of these, this energy is considered as a safe economic option.
\end{abstract}

Keywords: Nuclear Energy, Nuclear Fission, Fossil Fuel, Greenhouse Effect

\section{Introduction}

The increasing and increasing use of various energy carriers, such as oil, gas and coal, has attracted the attention of countries to two major problems, namely the end of fossil fuels, as well as environmental pollution. Hence, one of the main priorities of energy policy is diversification of energy sources, as well as finding a safe, cheap and free of greenhouse gases (Saltin and GhaffariSomee, 2016). Due to limited resources and unsustainable fossil fuels (oil, coal and natural gas) and the emissions they produce in terms of air pollution, greenhouse gases and ash to produce this fuel remains a major share in energy production. However, due to the growing need for energy, can be used as a new energies such as nuclear energy (Zaheri_Abdevand and Zaheri_Abdevand, 2016). It is well known that man has established his dominance over a force that superior to all material phenomena in the world, so that he has been able to use this great force (Nuclear energy) both for 
development and construction of life and to destroy it. Today, most advanced countries use nuclear energy to generate electricity and provide energy, but they have not yet provided a sensible and rational solution to reduce radioactive contamination (Nowroozi, 2013). Differences of this study with previous studies, the separation of energy into fossil fuels, nuclear energy and renewable energy. This energy separation allows us to study the effects of nuclear energy and fossil fuels on the emission of pollutants. With global warming and environmental pollution in recent decades, all countries in the world have reached a consensus to take action to reduce environmental pollution and global warming (Stern, 2007; Adamantiades and Kessides, 2009; DeCanio, 2009; Reddy and Assenza, 2009). The purpose of this descriptive-analytic study is to provide two definitions of fossil fuels, nuclear energy and renewable resources, two hypotheses by the authors and try to find an answer to these two hypotheses. The hypotheses proposed by the authors are as follows: (1) The use of nuclear energy is safer and cheaper than fossil fuels. (2) The use of nuclear energy reduces emissions of greenhouse gases and reduces pollution. In the following, we will provide some explanations about the mentioned energies and in the following sections, theoretical foundations, methodology, findings and finally the discussion will be discussed.

\section{Energy Sources}

\section{Nuclear Energy}

Nuclear energy means atomic energy. To free this energy and use it, two processes can be used: Nuclear fission and nuclear fusion. Fission means breaking down the atomic nucleus into smaller and fission particles, the combination of atomic nuclei and the production of heavier nuclei (Zaheri_Abdevand and Zaheri_Abdevand, 2016).

\section{Application and Benefits of Nuclear Energy}

One of the major benefits of nuclear power is to prevent the many types of environmental problems caused by fossil fuels, oil, coal and gas. Nuclear power is a safe alternative to power generation (. With increasing energy consumption, concerns over warming will increase. So, we come to the conclusion that nuclear energy is reliable in this case and less damage to the environment and cheaper. Other benefits and applications of nuclear energy include.

\section{Nuclear Energy in Medicine}

Nuclear medicine is one of the branches of medical science used to diagnose and treat diseases.

\section{Nuclear Energy in Health}

If the raw materials are medicines, hygiene products and sterilized medical products, this contamination can be measured by radioactive materials.

\section{Nuclear Energy in Agriculture}

In agriculture, nuclear methods are used to repair seed of plants such as wheat, rice, corn, etc., so that they are resistant to fungal diseases, cold and other pests.

Nuclear energy in exploration: Here you can find the exact location of different mines and groundwater areas with the help of nuclear technology.

\section{Nuclear Energy in Power Generation}

Fossil fuels are not permanent resources and future generations will face a energy crisis, so the best solution is to build nuclear power plants and use nuclear fuel.

\section{Nuclear Energy in Security}

Mining exploration and surveying the density of bullets and mortars are possible with the help of nuclear-powered devices (; Movahednia et al., 2015).

\section{Nuclear Energy in Veterinary and Animal Husbandry}

Nuclear methods are used in the diagnosis and treatment of animal diseases, animal reproduction, livestock breeding in order to maximize yield, such as breeding cattle so that their usable meat can be maximized. On the health and safety of animal feed from radiation, can be used (Pourkhabbaz et al., 2013).

\section{Nuclear Energy in the Food Industry}

The quality of food, health and drinking is one of the things that can be determined by nuclear technology. Using atomic absorption systems to determine the amount of low toxicity in food, it is possible to detect food leakage. Proper irradiation of food causes pasteurization and sterilization and increases their shelflife (Pourkhabbaz et al., 2013).

\section{Nuclear Energy in Archeology}

Examples of archaeological examples, such as coins, pottery, etc., can be done to calm down and analyze them through nuclear science. To detect counterfeit samples of fossils and dating them, the amount of radioactive carbon found in the specimens is measured (Movahednia et al., 2015). It is also environmentally beneficial for the following reasons: It is a source of hazardous gases, such as $\mathrm{CO}_{2}, \mathrm{NO}_{2}$ and $\mathrm{SO}_{2}$ and does not cause global warming, Does not cause air pollution and acid rain production, If the number of reactors 
increases, it will increase the amount of fuel provided, The nuclear fission in this process is carbon-free and provides a significant portion of the world's energy, In spite of the menacing appearance of white masses coming out of the chimneys of nuclear power plants, they do not directly produce any kind of greenhouse gas, Nuclear reactors, in addition to power generation, have the potential for seawater desalination, regional heating and hydrogen fuel production, Construction of expensive nuclear power plants, but when they were built, their electricity prices would be cheaper than fossil fuel costs (Matin et al., 2013).

\section{Nuclear Energy Costs}

Among the nuclear energy complications are the following: The danger of electronic equipment, nuclear accidents, negative impact on health, undesirable effects on plant and animal life. In the meantime, the most serious nuclear energy problem is about nuclear waste (Movahednia et al., 2015). In the United States, nuclear waste is classified into three categories based on the type of material, the ability to generate heat and radiation intensity:

Low level wastes, are the most harmless radioactive substances that can withstand radiation for a short time. The source of these wastes is hospitals, laboratories and industry. The clothes of the employees involved with these materials and tools, filters, etc. are from this category of materials. Transuranic Waste, these waste products include chemicals such as chemical waste, metal claddings and many waste materials from nuclear power plants. These materials have a short life but need to be protected by special coatings. So these materials are placed between concrete blocks and stored in a special place. High-level waste, such as waste nuclear reactors, high-fission products and some high-tech heavy-duty components with a high half-life, can be considered as very difficult and cost-effective storage conditions (Agbalagba and Onoja., 2011; Asl-Hashemi and Mokhtari, 2008; Eskandari et al., 2012; The risk of nuclear waste can be greatly reduced or completely eliminated, provided that it is stored in a safe place before it is repaired (Ciullo et al., 2016). Sometimes possible It maintains solid nuclear waste in highly radioactive nuclear power plants for 50-40 years to reduce their activity to less than 1\% (Samadi, 2008). Some the methods for disposal of nuclear waste are as follows:

\section{Waste Explosion in Space}

Some scientists have considered space as the final area for destruction, especially for nuclear high-tech nuclear waste (Nowroozi, 2013). In this way, the radioactive material is placed in a rocket and sent to space so that it departs from the earth (Raczka, 2001).

\section{Landfill in the Sea and Ocean}

Atomic waste can be separated from the biosphere by burying it at the sea floor. The sea bed and the deep oceans are far from human activities, so they can be placed at a depth of 100-50 $\mathrm{m}$ of the ocean floor sediments to avoid human interference. In this way, international law is a major obstacle (Dabiri, 2000), the method has been used in Pakistan (Raczka, 2001).

\section{Landfill in Ice}

This method is proposed for materials with high radioactivity. Ice regions are far from humanoccupied areas and do not require the development of foreign and hidden technology. The disadvantages of this method are the unstable motion of the ice masses, as well as the increase of temperature and melting of the ice masses (Nowroozi, 2013; Bahmani and Azizi, 2016; Raczka, 2001).

\section{DeepInjection in Geological Formations}

This method is suitable for watery waste that is injected into pitting and slit layers at a depth of 5000$1000 \mathrm{~m}$ (Ghezeli and Dehghanian, 2014).

\section{Landfill in Salt}

Salt deposits are suitable for landfill and atomic waste, but the main problem in this way is to contact these wastewater with circulating groundwater (Ghezeli and Dehghanian, 2014).

\section{Burial in Tuff Stone}

This rock is a volcanic rock due to its tolerance and absorption quality. Scientists believe that this rock can be a high-level radioactive waste landfill (Ghezeli and Dehghanian, 2014). The best areas for solid landfill landfills are thick soils, clay rocks from clay deposition, hard rock, such as high-temperature granite rocks, resources Calcareous and dolomitic stones (Movahednia et al., 2015).

\section{Renewable Energy}

It is a kind of energy that, unlike non-renewable energies, is capable of returning to nature. It turns out that replacing this kind of energy with fossil fuels will save energy, control energy supply and demand and reduce greenhouse gas emissions. Renewable energies are important because of the benefits that they have, these benefits include: Renewable energy technology is a clean energy source and has less environmental impact, These resources are endless, The most investment in renewable energy is on materials and equipment, which makes them busy, These resources will reduce dependence on fossil resources and provide energy security for 
countries (Matin et al., 2013). The point about important renewable energy sources is attention to the limitations of these resources due to geographical location, weather conditions and annual and seasonal fluctuations, so these resources can not be alone provide energy, especially in large societies. Therefore, based on the experience gained in many countries, it seems that the only source that is able to supply energy for future generations as well as the control of greenhouse gas emissions is nuclear energy (Zaheri_Abdevand and Zaheri_Abdevand, 2016).

\section{Fossil Fuels}

Types of stored solar energy are called fossil fuels. These fuels come from the decomposition of organic materials. These fuels, which include oil, natural gas and coal, provide global energy consumption of about \%90 (Darwishi et al., 2016). It should be noted that these resources are limited and unsustainable and the high use of these resources has harmful effects on the environment (Zaheri_Abdevand and Zaheri_Abdevand, 2016). Today, there are growing concerns about fossil fuels and environmental pollution, which is the result of the burning of fossil fuels worldwide. Such as the incident in the Meuse Valley of Belgium, the incident of London and Los Angeles. So the world is more than ever to think of finding alternative energy sources and reducing the negative consequences of fossil fuels (Roudbari, 2001). Most of the energy consumed in the world is supplied by fossil fuels. These fuels have a variety of toxic and hazardous pollutants that enter the environment in many ways and ultimately the human food chain. Although the environmental impacts of the use of fossil fuels on surface water, groundwater, soil, air, vegetation, etc. are numerous, but the topic of air pollution and their greenhouse effects are more relevant (Darwishi et al., 2016; Zaheri_Abdevand and Zaheri_Abdevand, 2016) (Table 1).

\section{Air Pollution}

Combustion of fossil fuels enters a huge amount of $\mathrm{SO}_{\mathrm{x}}, \mathrm{NO}_{\mathrm{x}}, \mathrm{CO}$ and $\mathrm{CO}_{2}$ in the air (Zaheri_Abdevand \& Zaheri_Abdevand, 2016). This contamination can be in the form of smog, acid rain and particulate emerge (Zaheri_Abdevand and Zaheri_Abdevand, 2016; Roudbari, 2001).

\section{Greenhouse Effect}

Combustion of fossil fuels is the main source of greenhouse gas emissions to the atmosphere (Roudbari, 2001). This phenomenon increases the temperature of the Earth, melting the polar ice and raising the surface of the water (Zaheri_Abdevand and Zaheri_Abdevand, 2016).
Table 1: The share of fossil fuels in greenhouse gases emissions in 2013(\%) (

\begin{tabular}{lllllllll}
\hline Gas Fuel & $\mathrm{NO}_{\mathrm{x}}$ & $\mathrm{SO}_{2}$ & $\mathrm{SO}_{3}$ & $\mathrm{CO}$ & $\mathrm{SPM}$ & $\mathrm{CO}_{2}$ & $\mathrm{CH}_{2}$ & $\mathrm{~N}_{2} \mathrm{O}$ \\
\hline Liquid gas & 0.08 & 0.002 & - & 0.16 & - & 1.42 & 0.33 & 0.13 \\
Gasoline & 17.33 & 2.33 & - & 95.74 & 7.9 & 10.12 & 47.53 & 22.9 \\
Kerosene & 0.11 & 0.61 & - & 0.04 & - & 1.82 & 0.75 & 0.75 \\
Gas oil & 44.43 & 35.31 & 55.4 & 1.81 & 76.02 & 19.46 & 8.96 & 64.72 \\
Fuel oil & 9.63 & 60.25 & 42.6 & 1.15 & 4.59 & 12.63 & 4.04 & 4.02 \\
JP4 & 0.04 & 0.01 & - & 0.21 & 0.02 & 0.02 & 0.002 & 0.03 \\
ATK & 1.94 & 1.45 & 1.91 & 0.11 & 4.48 & 0.62 & 0.04 & 0.85 \\
Natural & 26.46 & 0.04 & - & 0.79 & 7 & 51.91 & 35.62 & 4.76 \\
gas & & & & & & & & \\
\hline
\end{tabular}

\section{Fundamentals and Theoretical Framework}

This section of the paper is to explain the key words to describe their research and approaches are discussed to explain the subject matter of and response to the hypothesis presented.

\section{Nuclear Energy}

The released thermal energy is due to fission of the uranium atom, which is used to generate water vapor and turn off power turbines (Ebrahimpour, 2008).

\section{Nuclear Fission}

A process in which a heavy atom such as uranium is converted into two lighter atoms. When a nucleus with a large atomic number is split, according to the Einstein formula $(E=m c 2)$ some of its mass is converted into energy (Chakam and Abadian, 2014).

\section{Fossil Fuels}

These fuels are caused by the incomplete degradation of dead organic matter (most of the plants and marine organisms). These organic materials are converted into hydrocarbons and fossil fuels through complex chemical reactions (Zaheri_Abdevand and Zaheri_Abdevand, 2016).

\section{Greenhouse Effect}

In this phenomenon, greenhouse gases in the Earth's atmosphere store a fraction of the solar energy that has been emitted into the atmosphere inside the atmosphere and the Earth's temperature remains constant at the appropriate level. This action calls greenhouse gases a greenhouse effect (The air inversion and greenhouse effect). One of the challenges of the 21 st century is the environmental crisis. Most of the environmental problems of the current century have been created due to the increased consumption of fossil fuels (MoghimiFeyzAbadi et al., 2011). Many studies have been done about the types of energy. Following global moves towards more environmental pollution than previous decades, consideration of environmental damage caused by the energy sector is essential. In this regard, it is important to pay attention to the amount of emissions and greenhouse gases in choosing the type of energy that has the least damage to the environment. 


\section{Research Method}

Due to limited energy resources and technological advances, the use of nuclear energy is increasing day by day. In this research, two hypotheses are proposed by the authors and the goal is to find an answer to these two hypotheses. The hypotheses proposed by the authors are as follows:

1. The use of nuclear energy is safer and cheaper than fossil fuels

2. The use of nuclear energy reduces greenhouse gas emissions and reduces pollution

The methods for collecting information in this research are as follows:

1. Library Method: By collecting descriptive information from books and library resources

2. Use of conference papers and scientific papers published in prestigious journals and to analyze and compare the results of studies

3. Examining National Bases (SID, Google Schoolar, Magiran, Iranmedex) and International (Sciencedirect)

\section{Findings and Outcomes}

Following the search for structured keywords in online databases, 85 articles were retrieved. After removing 33 duplicate articles, 52 eligible articles were selected for further analysis. The results show that with the passage of time the number of articles in the area of environmental effects caused by the consumption of energy, especially fossil fuels has increased. We will look at some of these studies. Abdoli and Yadqar (2006), state that the use of fossil fuels can cause emissions of greenhouse gases and environmental pollutants. In this research, while recognizing the energy and environment issues, alternative fossil fuel policies are being explored. The research findings showed that removing energy subsidies and targeting them would be an effective step in protecting the environment. Also, the effectiveness of increasing energy efficiency is high and the government can achieve large savings through small investments. Schneider (1989) studied the effects of greenhouse gas emissions. Because global warming caused by greenhouse gases has become an important issue and political science. From 1850, due to the combustion of fossil fuels and unsustainable use of land (mainly deforestation), $\mathrm{CO}_{2}$ levels have increased and consequently other greenhouse gases emissions such as methane and chlorofluorocarbons are also rising. Following studies, scientists have claimed that a heating signal is coming to the earth and most recent weather models represent the principle that global temperatures will rise from $2^{\circ} \mathrm{C}$ to $6^{\circ} \mathrm{C}$ over the next century. Barbir et al. (1990) studied the environmental damage caused by the use of fossil fuels. The purpose of this study is to identify the negative effects of using fossil fuels and assess their significance. According to this study, the cost of using fossil fuels is extremely expensive and not cost-effective. Also, these energies are not compatible with the environment and ruin it creates context, so using of the alternative energies and environmental protection are recommended. Moattar et al. (2007) compared the comparative economics of nuclear and fossil power generation. For this purpose, Shahid Rajaee fossil Powerhouse was selected in Qazvin, whose total capacity is like a $1000 \mathrm{MW}$ nuclear powerhouse. For this comparison, the cost of building a powerhouse, the annual fuel cost (Rials), the cost of repairing the heater powerhouse, the cost of producing the nuclear powerhouse, the cost of the fuel cycle, the cost of buying a yellow cake, the cost of enrichment, the cost of producing fuel rod and Shipping and post-cycle costs were calculated. According to the results of "Table 2", it can be concluded that the final price of electricity produced by the nuclear powerhouse is competitive with the most common fossil powerhouse (Steam powerhouse). A very important point in comparing these powerhouse is their environmental consequences, which are quantitatively referred to in "Table 2 " as the social costs. If these costs added to the price of electricity generated by powerhouse, nuclear powerhouse is cheaper than fossil power plant is economically feasible. KazemiRad et al. (2008) examined the nuclear energy alternative to fossil fuels have economic and environmental perspective. In this study, taking into account the 800 million dollars in fuel costs and 100 million dollars in maintenance costs, fuel costs a planthouse fossil $1000 \mathrm{MW}$ is between 400 to 700 million dollars but fuel a powerhouse nuclear $1000 \mathrm{MW}$ is 10 million dollars and in the worst 25 million dollars. According to these calculations, in the most pessimistic case of fuel costs for a nuclear power house is only $10 \%$ of the similar fossil fuel cost and in this respect nuclear energy is considered as a safe economic option.

Table 2: Price of electricity generated by power plants in terms of social costs (kwh / Rial)

\begin{tabular}{llcc}
\hline Type of powerhouse & $\begin{array}{l}\text { Electricity generated } \\
\text { (a) }\end{array}$ & $\begin{array}{l}\text { Social costs } \\
\text { (b) }\end{array}$ & $\begin{array}{l}\text { Final price of electricity } \\
(\mathrm{a}+\mathrm{b})\end{array}$ \\
\hline Heater & 156.25 & 180 & 336.25 \\
Combined cycle & 161.76 & 153 & 314.76 \\
Nuclear & 152.00 & 40 & 192.00 \\
\hline
\end{tabular}


In a study, the impact of nuclear energy on the amount of $\mathrm{CO}_{2}$ as an indicator of environmental quality in the period 2014-2004 was addressed. The results showed that nuclear energy consumption had a negative and significant effect on $\mathrm{CO}_{2}$ emissions (Saltin and GhaffariSomee, 2016). In a study China's nuclear power industry has been a major achievement of the country over the past three decades. China has faced serious challenges, such as environmental protection and the problems associated with the use of fossil fuels, so actions to promote the nuclear energy industry in pursuit of sustainable development (Zeng et al., 2016). In 2015, the relationship between nuclear energy consumption and economic growth was monitored in 15 countries. The results for the 1980s and 1980s show that there are no causal relationships between nuclear energy use and economic growth in ten of the 15 countries. Although in five other countries, there is a significant causal relationship between nuclear energy consumption and economic growth (Ozcan and Ari, 2015). Economic analysis of the relationship between energy and the environment in Japan shows that the main focus is on electricity generation 2030 is nuclear energy. The options provided by the government are improving energy efficiency, increasing renewable energy and reducing $\mathrm{CO}_{2}$ emissions. The economic analysis presented in this study contributed to Japan's future energy and environmental policy (Homma and Akimoto, 2013).

In a study of the impact of the state's economic policies on the quality of the environment in seven countries Iran, Syria, Algeria, Egypt, Jordan, Morocco and Tunisia from the Middle East and North Africa region (MENA), was examined during the period 19972007. In this study, carbon dioxide emissions and airborne concentrations were considered to be indicators of air pollution. The results of this study showed that government investments were a major factor in determining the amount of carbon dioxide emissions (Shahab and Nasser Sadrabadi, 2013). The study examined the relationship between nuclear power consumption, economic growth and $\mathrm{CO} 2$ emissions during the period 2010-2015. The results showed that nuclear energy has a reciprocal and significant effect on $\mathrm{CO} 2$ emissions. The results also indicate a two-way causality relation between nuclear power consumption and economic growth (). In 2012, a very comprehensive study was conducted on nuclear power plants and the cost of fossil and nuclear power was compared. The results showed that the production of nuclear is superior to fossil fuels, if external costs include greenhouse gas emissions (Shojaee et al., 2012). The study also examined the long-term impact of economic development and financial development on the environmental quality of the selected OPEC member countries. The empirical results obtained during the period of 1973-2007 show that the financial development indicators for carbon dioxide emissions are negatively affected as a criterion for environmental quality (Asghar-Pour et al., 2013). Other studies on nuclear energy can be found on Saed (1999-2000; 2004), Shafe (1998), Alizadeh (1987), Saidi and Ben Mbarek (2016), Min et al. (2014), Apergis and Payne (2010), Menyah and Wolde-Rufael (2010) and MohammadvandNahidi and AliPour (2010).

\section{Discussion}

The study was carried out with the aim of investigating the environmental and economical effects of different types of energy. Literature reviews showed that both qualitative and quantitative subject of interest was considered. In this article, descriptive and analytical method was selected. The required information was collected through journals, dissertations, research papers and scientific bases and then, the different types of energy cost in order to meet human energy needs were discussed. The strong dependence and growing demand for energy sources, which is a key factor in growth and economic activity, on the one hand and the limitation of fossil fuels on the other, justifies the world's future energy supply. Hence, the world is struggling to overcome this energy shortage and turn to new energies, especially nuclear power. Excessive use of fossil fuels by humans causes emissions of greenhouse gases and environmental degradation and pollution. The most important alarming alarm on the impact of human injuries on the environment is the pollution of air, soil, rivers and seas with toxic and deadly substances (Matin et al., 2013). Today, the increasing trend of the use of nuclear technology in various sectors of research, industry, agriculture, medicine, etc. has led (Sabzghabaee and Dadvar, 2015) that the use of nuclear energy would be as compromised as possible between the right to development and environmental observance. With the explanation that one of the principles that is nowadays in international law is the principle of sustainable development, according to this principle, economic development must be carried out in such a way that it has the least negative impact on the environment (Ilderomy and Norouzifard, 2013). The development of technology and the efforts of the international community have shown that the 
benefits of using nuclear energy are increasing day by day and increasing its desirability. Although it seems that some disadvantages such as radioactive waste will be seriously addressed for a long time. In general, in the context of the increasing development of nuclear technology and the observance of international requirements for its use, a fairly clear prospect for the use of nuclear energy can be outlined (Ilderomy and Norouzifard, 2013).

\section{Conclusion}

Enabling energy, economic progress and increasing the welfare of the people. Most of the energy needed to date has been required from fossil fuels. These resources are limited and contaminated after consumption. One of the most important problems caused by fossil fuels, which has attracted the most attention, is the warming of the earth and climate change, as well as acid rain that has devastating effects on forests and aquatic plants. Humans by using fossil fuels, generate greenhouse gases and thereby offset the energy balance of the earth. Nuclear power serves as one of the environmental approaches to cope with global warming and lower environmental pollution caused by fossil fuels. Nuclear energy is a safe, clean and inexpensive substitute for power generation and should not allow false information and tactics to make people fearful about using this energy efficiently. The development of technology and the efforts of the international community suggests that day to day the benefits of using nuclear energy will increase its disadvantages and increase its utility. However, it seems that some disadvantages such as industrial wastes will be seriously addressed for a long time. In general, in the context of the growing development of nuclear technology and the observance of international requirements for its use, a relatively clear outlook for the use of nuclear energy can be outline(Salimi-Torkamani, 2012). Nuclear powerhouse do not have environmental pollution. The only problem with these powerhouse is their nuclear waste, which does not pose a particular risk if they respect their safety and landfill principles in nonresidential areas far from humans. Also, the important advantages of nuclear fuel are that this fuel prevents the occurrence of a variety of environmental problems caused by coal fuels, oil and gas. The answer to this question which of fossil fuels or nuclear fuels has more environmental benefits is due to the waste generated in each of these fuels lies. With the production of nuclear energy, no other material is burned in the true sense. Heat is generated through nuclear fissures, not oxidation. Nuclear energy, in fact, helps to save the environment by removing nuclear waste that is usually suspended in the air. Nuclear reactors also given amount of fuel, produce the nuclear wastes. These fuels used in the fuel tank of the reactor are maintained (unlike fossil fuels that send the gases into space, solid waste generated by nuclear fuel will be maintained throughout the reactor fuel production process and in Finally, no smoke or garbage enters the space). It is clear that the best means of choosing energy systems is to select the system that has the lowest cost, both in terms of the costs that the electricity consumers have to pay and the costs imposed on the whole society (Uic Nuclear Issues, 2004a; 2004b). In general, the costs of associated with the construction and investment of nuclear powerhouse are higher of the cost for building fossil powerhouse. But when the nuclear powerhouse was built and exploitation, low cost economic variables, so that the use of nuclear energy is more economical from the other systems. Based on the analysis and study of the studies carried out and their comparison, it can be said that the use of nuclear energy is economically more cost effective than other energies, as well as producing none of the greenhouse gas produced by fossil fuels and thus reduces the pollution of the environment.

\section{Acknowledgement}

Thanks to all the colleagues and professors who contributed to the writing and writing of this research.

\section{Funding Information}

All costs related to the preparation and preparation of this article are paid by the authors..

\section{Author's Contributions}

In writing this article, the authors had an equal share of participation and participated in all stages, including writing, editing, arbitration and all stages of scientific work.

\section{Ethics}

In this article, all ethical principles related to scientificresearch articles such as: Validity and authenticity, originality, data collection in a standard manner, integrity and accuracy of research and ... are observed. 


\section{References}

Abdoli, M.A. and A.M, Yadqar., 2006. Energy, Environment and Development, J. Iranian Energy.

Adamantiades, A. and I. Kessides, 2009. Nuclear power for sustainable development: Current status and future prospects. Energy Policy, 37: 5149-5166. DOI: 10.1016/j.enpol.2009.07.052

Agbalagba, E.O. and R.A. Onoja, 2011. Evaluation of natural radioactivity in soil, sediment and water samples of Niger Delta (Biseni) flood plain lakes, Nigeria. J. Environ. Radioactivity, 102: 667-671. DOI: 10.1016/j.jenvrad.2011.03.002

Alizadeh, H., 1987. Landsat satellite depicts the Chernobyl nuclear explosion. J. Growth Geography Educ., 3: 32-37.

Apergis, N. and J.E. Payne, 2010. A panel study of nuclear energy consumption and economic growth. Energy Econom., 32: 545- 549.

DOI: 10.1016/j.eneco.2009.09.015

Asghar-Pour, H., D. Behbodi and R. Mohammadi Khanaghahi, 2013. The effect of economic development and financial development on environmental quality in selected OPEC members. J. Environ. Econom. Energy, 2: 1-26.

Asl-Hashemi, M. and S. Mokhtari, 2008. Management methods of radioactive waste in the environment (water, air and soil) and related diseases. Proceedings of the 2nd Specialized Conference on Environmental Engineering, (CEE' 08), Tehran, pp: 1-5.

Bahmani, A. and P. Azizi, 2016. Study of nuclear energy and the effects of nuclear pollution on the environment and human beings. Proceedings of the 1st National Conference on Power Engineering and Nuclear Power Plants, (NPP' 16), pp: 2-16.

Barbir, F., T.N. Veziroglu and H.J. Plass- Jr, 1990. Environmental damage due to fossil fuels use. Int. J. Hydrogen Energy, 15: 739- 749.

DOI: 10.1016/0360-3199(90)90005-J

Chakam, A. and M. Abadian, 2014. Nuclear energy and its effects on the environment. Proceedings of the Iranian Conference on Environment and Energy, (CEE' 14), International Institute for Educational and Researches of Kharazmi, Shiraz, Iran, p: 1-2.

Ciullo, G., R. Engels, M. Buscher and A. Vasilyev, 2016. Nuclear Fusion with Polarized Fuel. 1st Edn., Springer, ISBN-10: 3319394703, pp: 154.

Dabiri, M., 2000. Environmental pollution (air, water, soil, sound). Publication of the Alliance, Tehran.
Darwishi, E., M. Salari-Khales, K. YarMohammadi and S. Pour-Nosrat, 2016. Investigating the environmental impacts of fossil fuels on sustainable urban development Case study: Ardebil. Proceedings of the 2nd International Conference on Information and Communication Technology and Management, (CTM' 16), Superior Service Company, Tehran.

Decanio, S.J., 2009. The political economy of global carbon emissions reductions. Ecol. Econom., 68: 915-924. DOI: 10.1016/j.ecolecon.2008.10.003

Ebrahimpour, R., 2008. Investigating the relationship between causality between energy consumption and economic growth. MSc Dissertation, Tabriz Azad University.

Eskandari, R., N. Hafezimoghadas and H.R. HeidariSuluklui, 2012. EIA evaluation of the landfill of hazardous reference wastes in central Iran. Proceedings of the 16th Conference of the Iranian Geological Society, (IGS' 12), Shiraz University.

Ghezeli, F.D. and S. Dehghanian, 2014. The Economics of Natural Resources, Environment and Policies. 1st Edn., Ferdowsi University Press, Mashhad, ISBN: 9789645782434

Homma, T. and K. Akimoto, 2013. Analysis of Japan's energy and environment strategy after the Fukushima nuclear plant accident. Energy Policy, 62: 1216-1225.

DOI: $10.1016 /$ j.enpol.2013.07.137

Ilderomy, A. and P. Norouzifard, 2013. Environmental risks of nuclear energy. Proceedings of the 1st Conference on Environmental, Energy and Clean Industry, (ECI' 13), University of Tehran, Tehran, pp: $1-8$.

KazemiRad, L., M. Panahandeh and N. Abedinzadeh, 2008. A survey on the replacement of nuclear energy with fossil fuel from an economic and environmental perspective. Proceedings of the National Conference on Fuel, Energy and Environment, (FEE' 08), Materials and Energy Research Center, Tehran.

Matin, S., M. Bahnameh and A. Yazdi, 2013. Study of the environmental effects of renewable and nuclear energy. Proceedings of the National Conference on Environmental Research, (CER' 13), Hamadan, pp: 1-15.

Menyah, K. and Y. Wolde-Rufael, 2010. $\mathrm{CO}_{2}$ emissions, nuclear energy, renewable energy and economic growth in the US. Energy Policy, 38: 2911-2915. DOI: $10.1016 /$ j.enpol.2010.01.024 
Min, B.L., R. Perianez, K. Park, I.G. Kim and K.S. Suh, 2014. Assessment in marine environment for a hypothetic nuclear accident based on the database of tidal harmonic constants. Marine Pollut. Bull., 87: 269-275.

DOI: 10.1016/j.marpolbul.2014.07.045

Moattar, F., Z. Abedi and A. Vaziri-Nahad, 2007. Economic and environmental comparativeof nuclear and fossil fuels in Iran. Proceedings of the National Energy Conference, (NEC' 07), National Energy Committee of the Islamic Republic of Iran, Department of Electricity and Energy Ministry of Energy, Tehran.

Mohammadvand-Nahidi, M.R. and H. AliPour, 2010. The impact of economic growth and oil prices on nuclear power consumption. Financial Econom. Q., 4: 26-9.

Moghimi-FeyzAbadi, M., N. Shah-Noushi, S.H. Danesh, B.A. Akbari-Moghaddam and M. Daneshvar, 2011. The study of the welfare and environmental impacts of green taxes and the reduction of fuel subsidies in Iran, using a computable general equilibrium model. J. Agric. Dev. Econom., 19: 99-108.

Movahednia, A., A. SedghKordar, A. Ramezani and H. Abbasi, 2015. Effects of radioactive materials on the environment. Proceedings of the 3rd Conference on the Environment, Energy and Biological Defense, (EBD’ 15), Higher Education Institution, MehrArvand, Promotional Group of Environmental Lovers, Tehran.

Nowroozi, S., 2013. Environmental effects of radioactive materials (nuclear energy). Proceedings of The 1st national Conference on Architecture, Restoration, Urbanization and Sustainable Environment, (USE' 13), Hegmataneh Environment Assessment Center, Hamadan, pp: 1-20.

Ozcan, B. and A. Ari, 2015. Nuclear energy consumption-economic growth nexaus in OECD: A bootstrap causality test. Proc. Econom. Finance, 30: 586-597.

DOI: $10.1016 / \mathrm{S} 2212-5671(15) 01271-\mathrm{X}$

Pourkhabbaz, H.R., S. Javanmardi and N. Mirzaei, 2013. Environmental study of nuclear energy, Environmental study of nuclear energy. Proceedings of the National Conference on Environment, Energy and Biological Defense, Educational institute of Mehr Arvand, Promotion Group of Environmental Lovers, Tehran, Iran.

Raczka, J., 2001. Explaining the performance of heat plants in Poland. Energy Econom., 23: 355-370 DOI: $10.1016 / \mathrm{S} 0140-9883(00) 00076-1$
Reddy, B.S. and G.B. Assenza, 2009. The great climate debate. Energy Policy, 37: 2997-3008.

Roudbari, A.A., 2001. Fossil fuels and its effects on the environment. Proceedings of the International Fuel Conservation Optimization Conference in Building, Iran Fuel Conservation Organization, Tehran.

Sabzghabaee, G.R. and A. Dadvar, 2015. Study on the environmental effects of nuclear radioactive materials. Proceedings of the 3rd Conference on the Environment, Energy and Biological Defense, Higher Education Institution of MehrArvand, Promotion Group of Environmental Lovers, Tehran, pp: $1-10$.

Saed, N., 1999-2000. Introduction to the CTBT. Quarterly Defense Policy, No. 30-29, Tehran.

Saed, N., 2004. Development of nuclear technological knowledge and technology in international law documents and teachings. Q. J. Defense Policy, 12: 45-72.

Saidi, K. and M. Ben Mbarek, 2016. Nuclear energy, renewabl e energy, $\mathrm{CO}_{2}$ emissions and economic growth for nine developed countries: Evidence from panel Granger causality tests. Progress Nuclear Energy, 88: 364-374.

DOI: $10.1016 /$ j.pnucene.2016.01.018

Salimi-Torkamani, H., 2012. The use of nuclear energy: Advantages, disadvantages and challenges ahead. Publishing Fanous.

Saltin, P. and N. GhaffariSomee, 2016. Effect of nuclear energy on environmental quality: Panel data approach. J. Sustainability Dev. Environ., 3: 57-66.

Samadi, A.S.A., 2008. Atomic energy, atomic power plants, atomic fuel and atomic enrichment and the environmental impact of radiation materials. The Institute of Cultural and World Art Book, Tehran, Iran.

Schneider, S.H., 1989. The greenhouse effect: Science and Policy. Science. 243: 771-781.

DOI: $10.1126 /$ science.243.4892.771

Shafe, M.S., 1998. Advisory opinion of the international court of justice on nuclear threats. J. Law Political Sci., 41: 156-129.

Shahab, M.R. and S.M. Naser-SadrAbadi, 2013. The effect of governmental economic policies on environmental quality in selected countries. J. Environ. Sci. Technol., 16: 139-150.

Shojaee, M., S. Nemazi and M. Birjandvand, 2012. Economic and environmental studies of fossil and nuclear power plants and provide optimal option. Financial Econom. Q., 7: 48-27. 
Stern, N., 2007. Review on the economics of climate change.

http://www.hmtreasury.gov.uk/sternreview_index.htm

The air inversion and greenhouse effect, https:// library.tebyan.net/fa/Viewer/Text/75009/1

UIC Nuclear Issues, 2004a. Energy analysis of power systems.

Briefing

Paper\#

57. www.uic.com.au/nip57.htm

UIC Nuclear Issues, 2004b. The economics of nuclear power. Briefing Paper \# 8. www.uic.com.au/nip08.htm.
Zaheri_Abdevand, A. and F. Zaheri_Abdevand, 2016. Modern nuclear energy analysis approach and environmental sustainability. Proceedings of the International Conference on Science and Engineering, (CSE' 16), Permanent Secretariat, Istanbul University, Turkey.

Zeng, M., S. Wang, J. Duan, J. Sun and P. Zhong et al., 2016. Review of nuclear power development in China: Environment analysis, historical stages, development status, problems and countermeasures. Renewable Sustainable Energy Rev., 59: 1369-1383. DOI: 10.1016/j.rser.2016.01.045 